\title{
Internal Validation of Rapid and Performance Method for Patulin Determination in Apple Cider by High-Performance Liquid Chromatography
}

\author{
MONICA CATANA ${ }^{1}$, LUMINITA CATANA ${ }^{1 *}$, ENUTA IORGA ${ }^{1}$, ADRIAN CONSTANTIN ASANICA², ANDA GRATIELA LAZAR ${ }^{1}$, \\ MONICA ALEXANDRA LAZAR ${ }^{1}$, NASTASIA BELC ${ }^{1}$, GINA PIRVU ${ }^{1}$ \\ ${ }^{1}$ National R\&D Institute for Food Bioresources -IBA Bucharest, 6 Dinu Vintila Str., 021102, Bucharest, Romania \\ 2University of Agronomic Sciences and Veterinary Medicine of Bucharest, Faculty of Horticulture, 59 Marasti Blvd, 011464, \\ Bucharest, Romania
}

\begin{abstract}
An analytical method was developed and validated for separation, detection and quantification of patulin in apple cider by high-performance liquid chromatography (HPLC-DAD). Extraction and clean-up of patulin from apple cider are achieved on AFFINIMIP ${ }^{\circ}$ SPE PATULIN cartridge $(3 \mathrm{~mL} / 100 \mathrm{mg})$. Patulin was separated on a C18 Hypersil GOLD column ( $150 \mathrm{~mm} \times 4 \mathrm{~mm}, 5 \mu \mathrm{m}$ ) coupled to a Hypersil Gold guard column (10 X $4.0 \mathrm{~mm}, 5 \mu \mathrm{m})$ using mobile phase consisting of water:acetonitrile $(95: 5, \mathrm{v} / \mathrm{v})$ and detected at $276 \mathrm{~nm}$. The method has a good sensitivity $(L O D=2.63 \mu \mathrm{g} / \mathrm{mL}$ and $L O Q=8.45 \mu \mathrm{g} / \mathrm{mL})$ and a good precision $(R D S(r)=$ $0.32 . .0 .91 \%$ for injection repeatability; $R S D(r)=1.05 \ldots .2 .98 \%$ for analysis repeatability intra-day; $R S D(R)$ $=1.35 \ldots .3 .24 \%$ for intermediate precision; $R S D(R)=1.64 \ldots .3 .86 \%$ for intra-laboratory reproducibility). The method was applied by analyzing samples of apple cider purchased from commerce. In case of $80 \%$ of the analyzed samples, patulin was not detected, and for the rest of them concentration of patulin was $<L O Q$.
\end{abstract}

Keywords: patulin, validation, HPLC-DAD, apple cider

Mycotoxins are toxic secondary metabolites produced by fungi that pose a potential hazard for food safety. Patulin is a mycotoxin produced by more than 60 species of fungi belonging to greater than 30 genera [1,2]. Patulin is produced mainly by Penicillium expansum, but and other fungi, including $P$. claviforme, $P$. urticae, $P$. patulum, Aspergillus clavatus, $A$. giganteus, Byssoclamys fulva, $B$. nivea, and Alternaria alternata [3]. Frequently found in the rotten tissues of apples, patulin accumulation correlates with apparent symptoms of blue mold. Apple blue mold usually starts with the invasion of $P$. expansum spores on the wounds of fresh apples. Such stem punctures, insect injuries, and bruises are created during the picking and handling operations in the apple orchard, until the final processing steps of products [4]. Apple juice and other derived fruit products achieved from apples infected by Penicillium expansum, are the main source of patulin. Tannous etal. [5] developed and validated a mathematical model for predicting the $P$. expansum growth under natural conditions on apples, with an acceptable precision. This model could be used by apple growers and fruit juice producers to anticipate growth of $P$. expansum during storage and apple processing [5].

Long-term consumption of patulin-contaminated fruit juice can cause serious health problems because this mycotoxin is thought to have mutagenic, neurotoxic, genotoxic, and immunotoxic effects to animals $[6,7]$. Initially identified as an antimicrobial agent, patulin was reclassified as mycotoxin in the 1960s because of its acute toxicity into human body [7]. Joint FAO/WHO Expert Committee on Food Additives established in 1995 a provisional maximum tolerable daily intake of patulin at $0.4 \mu \mathrm{g} / \mathrm{kg}$ body weight/day [8].

The LD50 of patulin ranges from 15 to $5 \mathrm{mg} / \mathrm{kg}$, being dependent on the mode of exposure to this contaminant and the route of ingestion [9]. The amount of patulin in apple products is a quality indicator of them concerning food safety. In case of apple juice and apple cider the maximum level of patulin, established by the European Commission [10] is $50 \mu \mathrm{g} / \mathrm{L}$.

Worldwide, the incidence of patulin contamination is a problem, especially in case of producers of apples and apple-based products, such as China, the EU, and the USA [11]. In a study, Harris et al. [12] have evaluated the concentrations of patulin in apple cider and apple juice produced and marketed by Michigan apple cider mills during 2002-2006 ( $n=493$ samples), using highperformance chromatography. Patulin was detected ( $>$ or $=4 \mu \mathrm{g} / \mathrm{L}$ ) in $18.7 \%$ of all cider mill samples, and 11 samples (2.2\%) having patulin concentrations of $>$ or $=50 \mu \mathrm{g} / \mathrm{L}$. In case of cider samples obtained from mills using thermal pasteurization, patulin was detected in $28.4 \%$ of samples, and in the case of those taken from mills using UV light radiation, in $13.5 \%$ of samples. Among retail grocery store samples ( $n=159$ ), in $23 \%$ of apple juice and cider samples, patulin was detected, and in case of 18 samples (11.3\%) concentration of patulin was $>$ or $=50 \mu \mathrm{g} / \mathrm{L}$.

This paper presents the internal validation of a rapid and performance method for patulin determination in apple cider by high-performance liquid chromatography (HPLCDAD). Moreover, assessing the patulin content of apple cider samples (purchased from commerce), was performed.

\section{Experimental part}

Materials and methods

Samples

Samples of apple cider were purchased from commerce.

*email: lumi_catana@yahoo.co.uk, Phone: +4021.210.91.28, +4021.211.36.39 


\section{Reagents}

The patulin solution certified reference material, $100 \mu \mathrm{g} /$ $\mathrm{mL}$ in chloroform (CRM 46914), HPLC grade acetonitrile, diethyl ether, ethyl acetate, methanol, glacial acetic acid, absolute ethanol ( $c \geq 99.7 \%, v / v)$ for HPLC and sodium hydrogen carbonate were purchased from Sigma-Aldrich. Also, Acrodisc ${ }^{\circledR}$ syringe filters Nylon membrane $(\varnothing=13$ $\mathrm{mm}$, pore size $0.2 \mu \mathrm{m}$ ) were purchased from SigmaAldrich. Ultrapure water was obtained in house using ELGA water ultrapurification system. AFFINIMIP ${ }^{\circledR}$ SPE Patulin cartridges ( $3 \mathrm{~mL} / 100 \mathrm{mg}$ ) have been obtained from Affinisep-Polyintell (Val-de-Reuil, France).

\section{Standard preparation}

Patulin standard solutions (concentration $10 \mu \mathrm{g} / \mathrm{mL}$ ) were prepared from the patulin solution certified reference material (100 $\mu \mathrm{g} / \mathrm{mL}$ in chloroform). For this purpose, an adequate volume of patulin solution certified reference material with a concentration of $100 \mu \mathrm{g} / \mathrm{mL}$ is pipetted into a $20 \mathrm{~mL}$ brown vial and evaporated to near dryness, under nitrogen atmosphere (using a heating block with a sample concentration system under a nitrogen atmosphere), at $40^{\circ} \mathrm{C} \pm 0.2^{\circ} \mathrm{C}$.

The obtained residue is immediately dissolved in an adequate volume of absolute ethanol, so as to obtain a patulin standard solution at a concentration of $10 \mu \mathrm{g} / \mathrm{mL}$. The obtained solution is homogenized for 5 min using Vortex type stirrer. This solution is stored in a freezer at $-15^{\circ} \mathrm{C}$, being stable for 60 days. To obtain patulin standard solution for calibration, in a $20 \mathrm{~mL}$ brown vial, are pipetted $500 \mu \mathrm{l}$ of patulin standard solution (concentration $10 \mu \mathrm{g} /$ $\mathrm{mL}$ ), which will be evaporated to near dryness under nitrogen atmosphere at $40^{\circ} \mathrm{C} \pm 0.2^{\circ} \mathrm{C}$. The obtained residue is immediately dissolved in $5 \mathrm{~mL}$ of ultrapure water with $\mathrm{pH}=4$ to give a patulin standard solution of $1 \mu \mathrm{g} / \mathrm{mL}$ concentration. The obtained solution is homogenized for 5 min using a Vortex type stirrer. This solution is stored in a freezer at $3-4^{\circ} \mathrm{C}$, being stable for 60 days. Using this solution, it was achieved a calibration curve, with seven patulin standard levels (with three replicate injections from each level), in concentration range from $6.25 \mu \mathrm{g} / \mathrm{L}$ to $400 \mu \mathrm{g} / \mathrm{L}$.

\section{Sample preparation}

The apple cider is degassed by sonicating sample for 1 hour. Then the degas apple cider is diluted $1: 1$ with water containing $2 \%$ of acetic acid. This solution is mixed and used as the loading solution. Clean-up of apple cider sample is based on Application Notebook for AFFINIMIP $® S P E$ Determination of patulin in cider [13]. Thus, the AFFINIMIP ${ }^{\circledR}$ SPE Patulin cartridge is preconditioned with $2 \mathrm{~mL}$ acetonitrile and $1 \mathrm{~mL}$ ultrapure water, then, $4 \mathrm{~mL}$ loading solution is pipetted in this cartridge. In order to remove interferences, $1 \mathrm{~mL}$ solution $\mathrm{NaHCO}, 1 \%$ in water and $2 \mathrm{~mL}$ ultrapure water were passed through the cartridge, then applied a vacuum for about 10s. Further, $500 \mu \mathrm{L}$ diethyl ether were passed through the cartridge, and finally patulin was eluted with $2 \mathrm{~mL}$ ethyl acetate. The elution fraction was then evaporated to near dryness under a nitrogen atmosphere at $40 \pm 0.2^{\circ} \mathrm{C}$, and dissolved in acetonitrile:ultrapure water $(\mathrm{pH}=4)=10: 90$. The final extract was filtered through $0.2 \mu \mathrm{m}$ Nylon syringe filters ( $\varnothing$ $=13 \mathrm{~mm}$ ) and $25 \mu \mathrm{L}$ were injected for HPLC analysis.

\section{Chromatographic conditions}

A Surveyor Plus (Thermo Finnigan) high performance liquid chromatograph (vacuum degasser, quaternary pump, autosampler with PELTIER sample temperature control, column compartment with PELTIER temperature control, Diode Array Detector, ChromQuest 4.2 software for data acquisition and data processing) was used for analysis of patulin. The separation was performed at $25^{\circ} \mathrm{C}$, on a C18 (Hypersil GOLD $150 \times 4 \mathrm{~mm}, 5 \mu \mathrm{m}$ ) with a Hypersil Gold guard column ( $10 \times 4 \mathrm{~mm}, 5 \mu \mathrm{m})$. The composition of mobile phase was water: acetonitrile $(95: 15, \mathrm{v} / \mathrm{v})$. The injection volume was $25 \mu \mathrm{L}$, the flow rate of the mobile phase was $1.0 \mathrm{~mL} / \mathrm{min}$ and the detection wavelength was $276 \mathrm{~nm}$. Peak identification was based on retention time, spectral information and spiking technique. Peak quantification was based on the external standard method, using calibration curve and ChromQuest 4.2 software [14]. In figure 1 is presented the chromatogram of the patulin standard (certified reference material), with the concentration of $50 \mu \mathrm{g} / \mathrm{L}$ (retention time $=4.605 \mathrm{~min}$ ).

\section{Validation study}

In the case of method for determination of patulin from apple cider it was achieved an in house validation study, being evaluated the following performance characteristics: linearity, accuracy, precision (repeatability, reproducibility), selectivity, sensitivity (limit of detection, limit of quantification) and uncertainty.

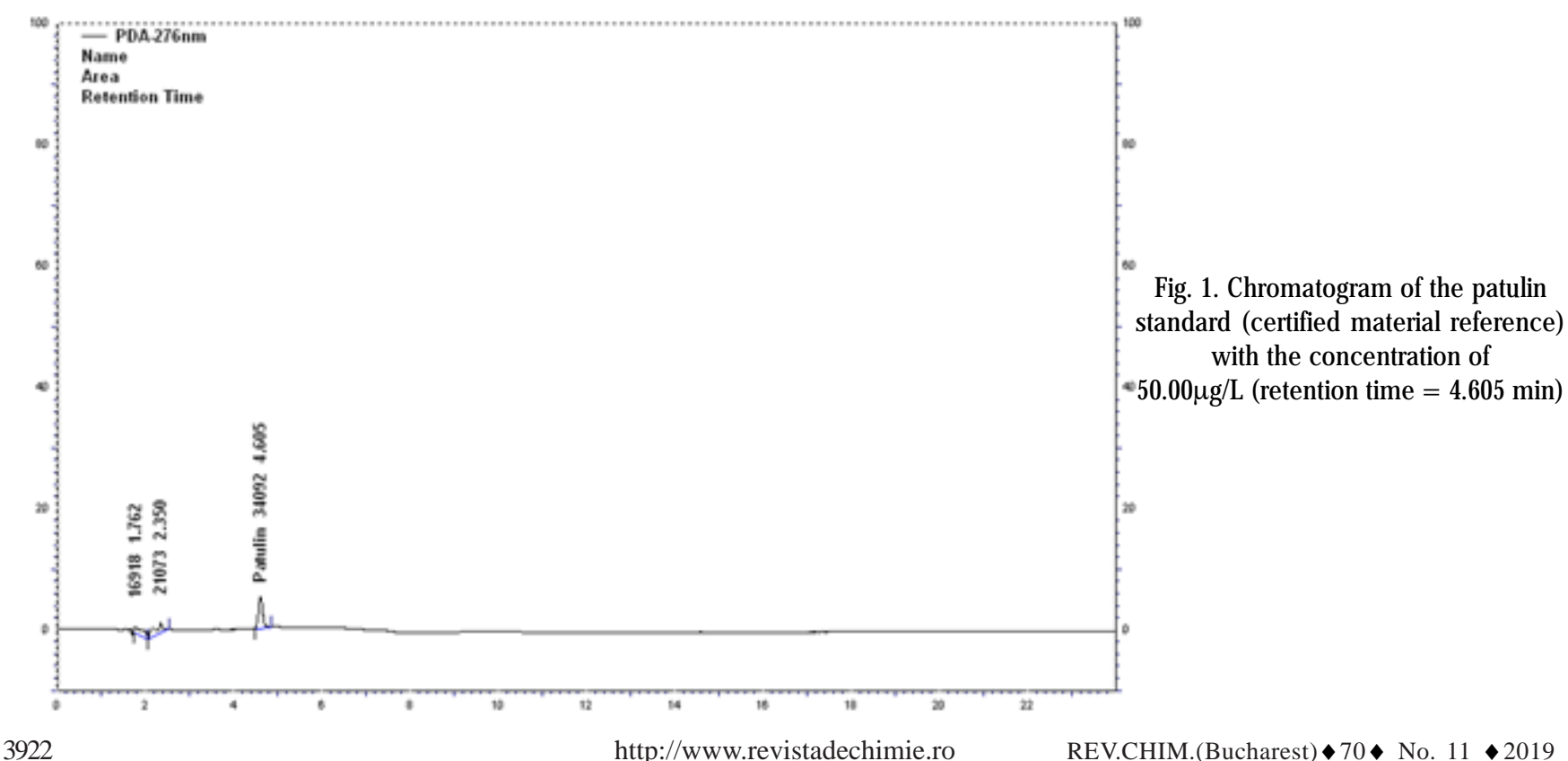




\section{Statistical analysis}

All analyses were performed in triplicate and the data are presented as mean \pm standard deviation. Regarding validation parameters, average for concentration values (expressed as $\mu \mathrm{g} / \mathrm{mL}$ ), standard deviation in repeatability $\mathrm{SD}(\mathrm{r})$ and reproducibility conditions $\mathrm{SD}(\mathrm{R})$, as well as relative standard deviation in repeatability $R S D(r)$ and reproducibility conditions $\mathrm{RSD}(\mathrm{R})$ in \% were calculated using Microsoft Excel.

\section{Results and discussions}

Performance of the method

Linearity

Linearity was investigated with the aid of a regression line with 7 calibration levels by the method of least squares, in concentration range from $6.25 \mu \mathrm{g} / \mathrm{L}$ to $400 \mu \mathrm{g} / \mathrm{L}$. Calibration curve of the patulin ( $y=696752 x-430.9)$ was linear over the range of $6.25 \mu \mathrm{g} / \mathrm{L}-400 \mu \mathrm{g} / \mathrm{L}$ and regression coefficient $\left(R^{2}\right)$ was 1.000 which proves a high linearity degree (fig. 2). The linearity was checked by the correlation coefficient (acceptance criteria: >0.990), the relative standard deviation (RSD, \%) of peak areas (acceptance criteria: $<1.5 \%$ ) at all the concentration levels, the RSD, $\%$ of retention times (acceptance criteria: $<0.5 \%$ ). Good response linearity was obtained for the patulin $\left(R^{2}>0.9999\right)$ in the range of concentrations $6.25 \mu \mathrm{g} / \mathrm{L}-400 \mu \mathrm{g} / \mathrm{L}$. The relative standard deviation (RSD, \%) of patulin peak areas was $0.1-1.3 \%$ and the relative standard deviation (RSD, $\%)$ of retention times was $0.04-0.12 \%$.

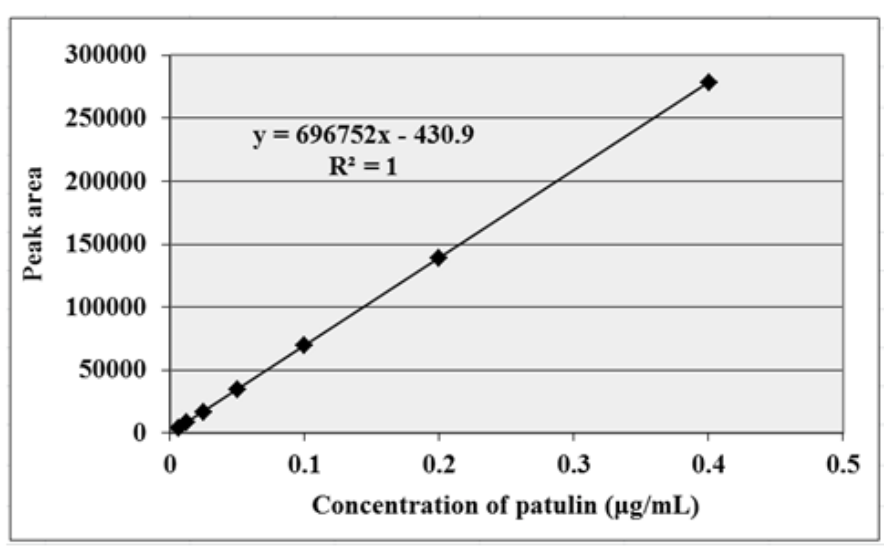

Fig. 2. Calibration curve of patulin

\section{Accuracy}

Accuracy was investigated by recovery. Apple cider samples in which patulin was not detected, were spiked with patulin (using patulin standard solution for calibration, with patulin concentration of $1 \mu \mathrm{g} / \mathrm{mL}$ ) in the following concentrations: $5 \mu \mathrm{g} / \mathrm{L}, 10 \mu \mathrm{g} / \mathrm{L}, 20 \mu \mathrm{g} / \mathrm{L}, 40 \mu \mathrm{g} / \mathrm{L}, 50 \mu \mathrm{g} / \mathrm{L}$, $60 \mu \mathrm{g} / \mathrm{L}, 80 \mu \mathrm{g} / \mathrm{L}$ and $100 \mu \mathrm{g} / \mathrm{L}$. These samples were analysed by HPLC method to determine patulin concentration (there were analyzed 7 parallel samples for each addition level, and each sample was analysed in triplicate). After performing HPLC analysis, the recovery of each patulin was calculated by $R(\%)=\left[\left(C_{2}\right) / C_{1}\right] \times 100$, where $R(\%)$ is percent recovery, $C$, is patulin concentration in the spiked sample, determined by HPLC analysis and $\mathrm{C}_{\text {. }}$ is the theoretical (conventionally true) concentration of patulin in the spiked sample. The obtained values for recovery, on the patulin concentration ranges, are presented in table 1 . In the concentration range of $5 \mu \mathrm{g} / \mathrm{L}$ to $100 \mu \mathrm{g} / \mathrm{L}$, mean recovery was $86.12 \%$.

\section{Table 1}

RECOVERY IN THE CASE OF METHOD FOR DETERMINATION OF PATULIN IN APPLE CIDERI

\begin{tabular}{|c|c|}
\hline $\begin{array}{c}\text { Recovery } \\
(\%)\end{array}$ & $\begin{array}{c}\text { Patulin concentration } \\
(\boldsymbol{\mu} \mathrm{g} / \mathrm{L})\end{array}$ \\
\hline 90.95 & $<20$ \\
\hline 86.54 & $20-50$ \\
\hline 80.88 & $>50$ \\
\hline
\end{tabular}

According to the obtained results, mean recovery, for the concentration ranges mentioned above, was under the provisions of the Regulation (EC) No. 401/2006 [15].

\section{Precision}

Precision was determined by repeatability (injection standards of patulin and analysis repeatability), intralaboratory reproducibility and intermediate precision (interday). Injection repeatability was achieved by carrying out 7 consecutive injections in a short period of time (the same day). Analysis repeatability (intra-day) was determined by 7 repeated analyses of the same sample, in the same day by the same analyst and under the same experimental conditions. Intermediate precision (inter-day) was carried out by repeated analyses of the same sample in 3 different days by the same analyst and under the same experimental conditions. For evaluating the intra-laboratory reproducibility, 6 samples of apple cider have been analyzed by two analysts (analyst A-3 samples, analyst B-3 samples), performed in the same laboratory and using the same instrument (table 2). Repeatability was expressed as relative standard deviation in repeatability conditions RSD

Table 2

PERFORMANCE PARAMETERS OF THE METHOD

\begin{tabular}{|c|c|c|c|c|}
\hline Performance parameter & Spiking level $(\mu \mathrm{g} / \mathrm{L})$ & $\begin{array}{c}\text { Mean value } \\
\text { concentration }(\mu \mathrm{g} / \mathrm{L})\end{array}$ & RSD (r), (\%) & RSD (R), (\%) \\
\hline $\begin{array}{c}\text { Injection repeatability } \\
\text { (patulin standard, CRM), } \\
\mathrm{c}=50 \mu \mathrm{g} / \mathrm{L})\end{array}$ & - & $49.87 \pm 0.16$ & 0.32 & - \\
\hline \multirow{2}{*}{$\begin{array}{l}\text { Injection repeatability } \\
\text { (apple cider) }\end{array}$} & 25.0 & $24.95 \pm 0.23$ & 0.91 & - \\
\hline & 50.0 & $50.07 \pm 0.33$ & 0.66 & - \\
\hline \multirow{3}{*}{$\begin{array}{l}\text { Analysis repeatability } \\
\text { (intra-day) }\end{array}$} & 12.5 & $12.25 \pm 0.36$ & 2.98 & \multirow{3}{*}{-} \\
\hline & 25.0 & $25.14 \pm 0.39$ & 1.56 & \\
\hline & 50.0 & $50.02 \pm 0.52$ & 1.05 & \\
\hline \multirow{3}{*}{$\begin{array}{l}\text { Intermediate precision } \\
\text { (inter-day) }\end{array}$} & 12.5 & $12.13 \pm 0.39$ & \multirow{3}{*}{ - } & 3.24 \\
\hline & 25.0 & $25.01 \pm 0.46$ & & 1.84 \\
\hline & 50.0 & $49.94 \pm 0.67$ & & 1.35 \\
\hline \multirow{3}{*}{$\begin{array}{l}\text { Intra-laboratory } \\
\text { reproducibility }\end{array}$} & 12.5 & $12.25 \pm 0.47$ & \multirow{3}{*}{ - } & 3.86 \\
\hline & 25.0 & $24.90 \pm 0.63$ & & 2.54 \\
\hline & 50.0 & $50.13 \pm 0.82$ & & 1.64 \\
\hline
\end{tabular}




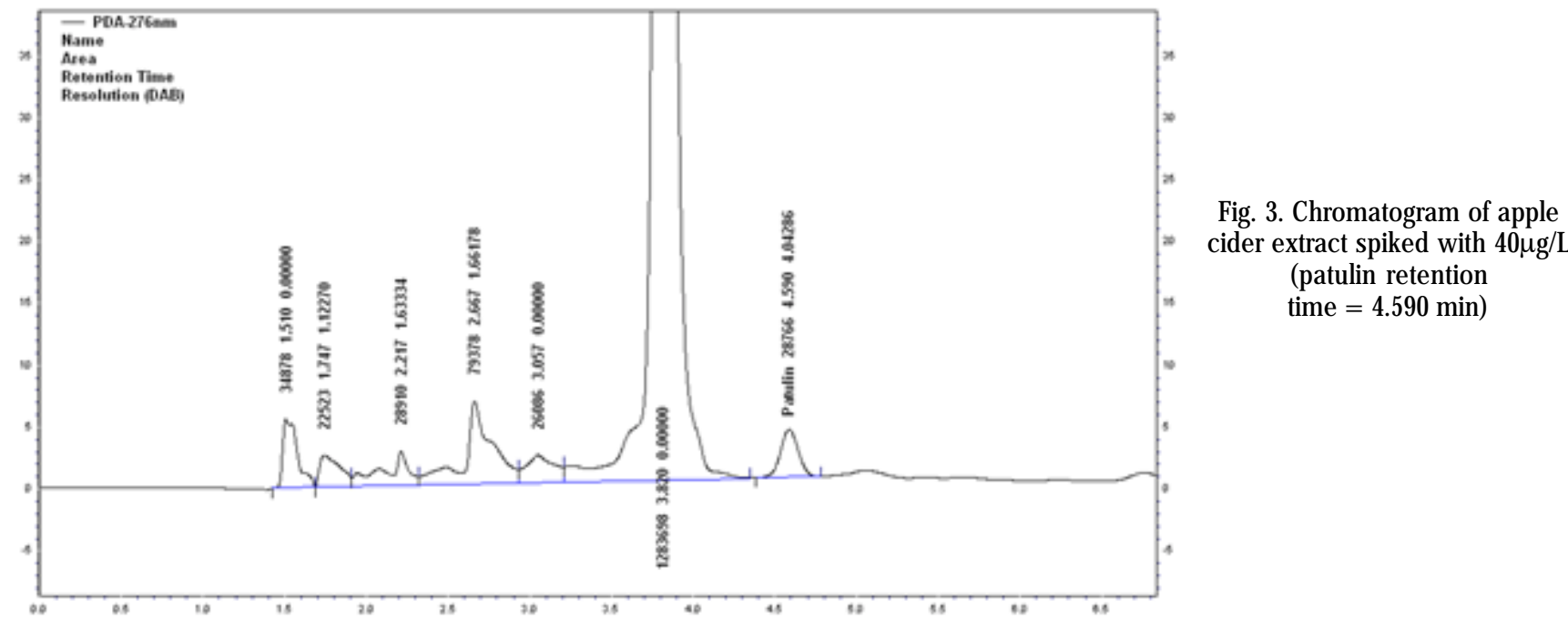

(r). Intra-laboratory reproducibility and intermediate precision w ere expressed as relative standard deviation in reproducibility conditions $\mathrm{RSD}(\mathrm{R})$. Performance parameters of the method are presented in table 2. Acceptance criteria for precision of the method for determination of patulin in apple cider are the following: relative standard deviation in repeatability RSD $(r)<2.00 \%$, relative standard deviation in repeatability analysis (intraday) RSD (r) $<3.00 \%$, relative standard deviation in intermediate precision (inter-day) RSD $(\mathrm{R})<3.50 \%$ and relative standard deviation in intra-laboratory reproducibility RSD $(R)<5.50 \%$. Acceptance imposed criteria for precision of the method are in accordance with the provisions of the Regulation (EC) No. 401/2006 [15]. The values obtained for injection and analysis repeatability, intermediate precision and intra-laboratory reproducibility showed a good precision (RSD < $5.5 \%$ ) of the method for determination of patulin in apple cider by high-performance liquid chromatography (HPLC-DAD).

Selectivity

Selectivity was demonstrated by chromatographic separation of patulin in the presence of other components from the apple cider (fig. 3). Peak corresponding to patulin is separated by baseline and by other compounds peaks. Resolution (DAB) is min. 2.7.

\section{Sensitivity}

Sensitivity was characterized by limit of detection (LOD) and limit of quantification (LOQ). Limit of detection (LOD) represents concentration at which signal/noise ratio is higher than $3(\mathrm{~S} / \mathrm{N}>3)$. Limit of quantification (LOQ) is defined as being the lowest concentration of analyte which can be determined with an acceptable precision, in the conditions of a method of analysis, at a signal/noise ratio higher than $10(\mathrm{~S} / \mathrm{N}>10)$. The $\mathrm{S} / \mathrm{N}$ ratio was calculated by the Chrom Quest 4.2 software. The criteria imposed for LOQ were: precision (expressed as relative standard deviation, $\mathrm{RSD} \leq 20 \%$ ) and accuracy (expressed as recovery in the range $80-120 \%$ ). The obtained results were as follows: $\mathrm{LOD}=2.63 \mu \mathrm{g} / \mathrm{L}$ and $\mathrm{LOQ}=8.45 \mu \mathrm{g} / \mathrm{L}$.

\section{Uncertainty}

The uncertainty sources were identified and analyzed and the uncertainty budget was estimated, according to the EURACHEM/CITAC Guide [16] and ISO/IEC Guide 983:2008 [17]. Expanded uncertainty (U) was calculated by multiplying the combined standard uncertainty (uc) with a coverage factor $(k=2)$ for a confidence level of $95 \%$.
Measurement uncertainty in case of the method for determination of patulin in apple cider was $\pm 10.55 \%$.

Method application

Method developed and validated was applied for determination of patulin content of apple cider samples purchased from commerce (15 samples). In case of 12 samples of apple cider patulin was not detected, and in case of 3 samples, concentration of patulin was < LOQ ( $\mathrm{LOQ}=8.45 \mathrm{ig} / \mathrm{L})$. In conclusion, samples of apple cider are in conformity with the provisions of the European Commission Regulation (EC) 1881/2006 [10].

\section{Conclusions}

An analytical method was developed and validated for separation, detection and quantification of

patulin in apple cider by high-performance liquid chromatography (HPLC-DAD). The proposed method has a good sensitivity $(\mathrm{LOD}=2.63 \mu \mathrm{g} / \mathrm{L}$ and $\mathrm{LOQ}=8.45 \mu \mathrm{g} / \mathrm{L}$ ) and allows determination with a good precision of patulin in apple cider. Following the analysis of patulin in the samples of apple cider purchased from commerce, it was found that this mycotoxin was not detected in case of $80 \%$ the samples, and in the rest of the samples concentration of patulin was < LOQ. In conclusion, the apple cider samples analyzed in this study are according to the provisions of the legislation into force [10].

Acknowledgements: This study was achieved through Core Program, with the support of the Ministry of Research and Innovation (MCI), contract 25N/2018, project PN 18020202.

\section{References}

1. BARUG, D., BHATNAGAR, D., VAN EGMOND, H.P., VAN DER KAMP, J.W., VAN OSENBRUGGEN, W.A., VISCONTI, A., The Mycotoxin Factbook, Wageningen Academic Publishers, Wageningen, 2006.

2. LAI, C., FUH, Y., SHIH, D., J. Food Drug Anal, 2, 2000, 2, p. 85.

3. DRUSCH, S., RAGAB, W., J. Food Prot, 66, 2003, p. 1514.

4. SANZANI, S., REVERBERI, M., PUNELLI, M., IPPOLITO, A., FANELLI, C., Int. J. Food Microbiol, 153, 2012, p. 323.

5. TANNOUS, J., ATOUI, A., KHOURY, A.El, FRANCIS, Z., OSWALD, I.P., PUEL, O., LTEIF, R., Food Science \& Nutrition, 4, no. 4, 2016, p. 611. 6. WOUTERS, M., SPEIJERS, G., Patulin Food Additives Series 35 Toxicological Evaluation of Certain Food Additives and Contaminants, vol. 35, Geneva: World Health Organization, 1996, p. 377.

7. MOAKE, M.M., PADILLA-ZAKOUR, O.I., WOROBO, R.W., Compr. Rev. Food Sci. Saf., 4, 2005, p. 8. 
8. *** World Health Organization. 1995. Evaluation of Certain Food Additives and Contaminants. 44th report of the Joint Food and Agriculture Organization/World Health Organization Expert Committee on Food Additives.

9. YANG, J., LI, J., JIANG, Y., DUAN, X., QU, H., YANG, B., CHEN, F., SIVAKUMAR, D., Crit. Rev. Food Sci. Nutr, 54, 2014, p. 64.

10. *** European Commission Regulation (EC) No. 1881/2006 of 19 December 2006 Setting Maximum Levels for Certain

Contaminants in Foodstuffs; Official Journal of the European Communities: Brussels, Belgium, vol. L364, 2006, p. 5.

11. *** USDA. Fresh Apples, Graps, and Pears: World Markets and Trade; United States Department of Agriculture: Washington, DC, USA, 2018.

12. HARRIS, K.L., BOBE, G., BOURQUIN, L.D., Journal of Food Protection, 72, no. 6, 2009, p. 1255.

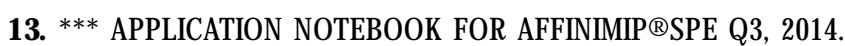
Selective Solid Phase Extraction Molecularly Imprinted Polymers for the Selective Extraction of Trace Analytes from Complex Matrices. 14. CATANA, M., CATANA, L., IORGA, E., NEGOITA, M., IONESCU, V., BELC, N., EFSTATIADE, D., ABOUL-ENEIN, H.Y., Journal of Environmental Science and Engineering, A 5, 2016, p. 371.

15. *** EUROPEAN COMMISSION. Regulation (EC) No 401/2006 of 23 February 2006 laying dow $n$ the methods of sampling and analysis for the official control of the levels of mycotoxins in foodstuffs, 2006b. 16. *** EURACHEM/CITAC Guide; Quantifying Uncertainty in Analytical Measurement, $3^{\text {rd }}$ ed.; UK, 2011.

17. *** ISO//EC Guide 98-3:2008: Uncertainty of Measurement - Part 3: Guide to the Expression of Uncertainty in Measurement (GUM:1995), ISO: Geneva, 2008.

$\overline{\text { Manuscript received: } 21.02 .2019}$ 